\title{
Níveis de energia metabolizável e lisina digestível sobre a composição e rendimento de carcaça de frangos de corte
}

\section{Metabolizable energy and digestible lysine levels on the composition and carcass yield of broilers}

\author{
Sharon Karla Lüders Meza $^{1 *}$; Ricardo Vianna Nunes ${ }^{2}$; Cláudio Yuji Tsutsumi³ \\ Flavio Medeiros Vieites ${ }^{4}$; Carina Scherer ${ }^{5}$; Jeffersson Rafael Henz ${ }^{6}$; \\ Idiana Mara da Silva ${ }^{7}$; Douglas Fernando Bayerle ${ }^{8}$
}

\begin{abstract}
Resumo
O objetivo deste estudo foi determinar a exigência nutricional de lisina digestível e energia metabolizável sobre o rendimento de carcaça e as taxas de deposição de proteína e gordura corporal de frangos de corte no período 35 a 49 dias de idade. Foram utilizados 768 frangos machos da linhagem Cobb 500, distribuídos em um delineamento inteiramente casualizado, em arranjo fatorial 4x4, contendo 16 tratamentos (4 níveis de lisina digestível x 4 níveis de energia metabolizável) e três repetições com 16 aves cada. Os níveis de lisina digestível e de energia metabolizável foram: 0,800; 0,900; 1,000 e 1,100\%

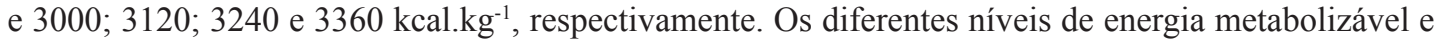
lisina digestível não influenciaram $(\mathrm{P}>0,05)$ o rendimento de carcaça de cortes (peito, coxa, sobrecoxa e asa) e de gordura abdominal. Houve interação $(\mathrm{P}<0,05)$ entre os níveis de energia metabolizável e lisina digestível sobre as taxas de deposição de proteína e gordura e o teor de gordura na carcaça dos frangos de corte. A taxa de deposição de gordura apresentou o melhor resultado para o nível de 1,000 $\%$ de LD e $3000 \mathrm{kcal}_{\mathrm{kg}}{ }^{-1}$ de EM. O maior teor de gordura ocorreu no tratamento com o maior nível de energia metabolizável (3360 kcal. $\left.\mathrm{kg}^{-1}\right)$. Os níveis de energia metabolizável e lisina digestível, contidos nas dietas de frangos de corte, no período de 35 a 49 dias de idade, não interferem no rendimento de carcaça e na quantidade de gordura abdominal.
\end{abstract}

Palavras-chave: Composição corporal, ração de terminação, rendimento de cortes

\footnotetext{
Abstract

The aim of this study was to determine the nutritional requirement of digestible lysine and metabolizable energy on carcass yield and protein and fat deposition rates of broilers in the period 35-49 days old. A total of $768 \mathrm{Cobb}$ male broilers were distributed in a completely randomized design, in a $4 \mathrm{x} 4$ factorial arrangement, totaling 16 treatments (4 levels of digestible lysine x 4 levels of metabolizable energy)

${ }^{1}$ M.e em Zootecnia, Universidade Estadual do Oeste do Paraná, UNIOESTE, Marechal Cândido Rondon, PR. E-mail: shakavet@, hotmail.com

2 Prof. Dr. em Zootecnia, UNIOESTE, Marechal Cândido Rondon, PR. E-mail: nunesrv@hotmail.com

3 Prof. Dr. em Agronomia, UNIOESTE, Marechal Cândido Rondon, PR. E-mail: claudio.tsutsumi@unioeste.br

${ }^{4}$ Prof. Dr. em Zootecnia, Dept ${ }^{\text {O }}$ de Medicina Veterinária, Universidade Federal de Juiz de Fora, UFJF, Juiz de Fora, MG. E-mail: fmvieites@yahoo.com.br

5 Bolsista do PNPD, PPZ UNIOESTE, Marechal Cândido Rondon, PR. E-mail: carina_scherer@hotmail.com

${ }^{6}$ M.e em Zootecnia, UNIOESTE, Marechal Cândido Rondon, PR. E-mail: jeffersson_henz@hotmail.com

7 Discente do Curso de Graduação em Zootecnia, UNIOESTE, Marechal Cândido Rondon, PR. E-mail: idi_idizinha@hotmail.com

${ }^{8}$ Discente do Curso de Mestrado em Zootecnia, UNIOESTE, Marechal Cândido Rondon, PR. E-mail: douglas fernandob@, hotmail.com

* Autor para correspondência
} 
and three replicates of 16 birds each. The digestible lysine and metabolizable energy levels were: 0.800 , $0.900,1.000$ and $1.100 \%$ and $3000,3120,3240$ and $3360 \mathrm{kcal}^{-\mathrm{kg}^{-1}}$ respectively. The different levels of metabolizable energy and digestible lysine did not influence $(\mathrm{P}>0.05)$ the carcass yield, parts (breast, thigh, drumstick and wing) and abdominal fat. There was an interaction $(\mathrm{P}<0.05)$ between the levels of metabolizable energy and digestible lysine on protein and fat deposition rates and carcass fat of broilers. The rate of fat deposition showed the best result for the level of $1.000 \% \mathrm{LD}$ and $3000 \mathrm{kcal} . \mathrm{kg}^{-1} \mathrm{ME}$. The higher fat content occurred in the treatment with the highest level of metabolizable energy (3360 kcal. $\left.\mathrm{kg}^{-1}\right)$. The metabolizable energy and digestible lysine levels contained in the diets of broilers in the period 35-49 days of age, do not interfere in the carcass and amount of abdominal fat.

Key words: Body composition, finisher diet, part yield

\section{Introdução}

A evolução e competitividade da indústria avícola têm buscado programas nutricionais diferenciados, com vistas ao suprimento exato de nutrientes das aves mediante o fornecimento de rações balanceadas. $\mathrm{O}$ aumento da produtividade e o faturamento dos segmentos agroindustriais estão diretamente relacionados às modificações nos processos produtivos que a indústria avícola vêm passando, decorrentes de inovações tecnológicas que englobam a qualidade da carne do frango, além do rendimento de carcaça e de suas partes.

O aminoácido lisina é fisiologicamente essencial para a mantença, crescimento e produção das aves e sua principal função é a síntese de proteína muscular. Está disponível na forma de cristalina e é facilmente analisado em laboratório (AJINOMOTO, 2012). Por isso, sua utilização foi escolhida por pesquisadores como referência para o perfil da proteína ideal sendo que as quantidades de todos os outros aminoácidos serão estabelecidas como uma proporção de sua exigência. Desta forma, qualquer erro na sua determinação acarretará erro na determinação dos outros aminoácidos, afetando no desempenho e qualidade da carcaça dos frangos de corte (BAKER, 2009).

O uso da lisina promove melhoria nos resultados de ganho de peso, conversão alimentar dos animais e os maiores rendimentos (carcaça, peito e porcentagem de gordura abdominal) (LABADAN; HSU; AUSTIC, 2001; KIDD et al., 2005). A utilização de L-Lisina na formulação das rações de frangos reduz a inclusão de ingredientes protéicos, favorece a entrada de mais ingredientes energéticos poupando o uso de óleo, mas mantém o mesmo nível de energia da ração, trazendo benefícios nos custos de produção (AJINOMOTO, 2012).

De acordo com Moreira et al. (2001), o aumento do nível de energia nas rações pode proporcionar melhor ganho de peso e conversão alimentar, no entanto, acarretará em aumento no teor de gordura abdominal, cujo excesso tem sido um problema para as indústrias, acarretando prejuízo na avicultura de corte. $\mathrm{O}$ excesso de gordura abdominal reduz o rendimento de carcaça e a eficiência alimentar das aves, mas também leva o consumidor à rejeição da carne de frango, visto que atualmente o mercado exige uma carne magra (GAYA; MOURÃO; FERRAZ, 2006).

A determinação da exigência nutricional de energia metabolizável é fundamental nas diferentes fases da criação de frangos de corte, já que a digestibilidade aumenta com a idade da ave devido ao desenvolvimento do trato digestivo, melhorando sua capacidade de aproveitamento dos nutrientes e da energia dos alimentos (MELLO et al., 2009).

Assim o objetivo deste trabalho foi avaliar o rendimento de carcaça e a deposição de gordura e proteína na carcaça de frangos de corte, com 35 a 49 dias de idade, alimentados com dietas contendo diferentes níveis de energia metabolizável e lisina digestível. 


\section{Material e Métodos}

Este trabalho foi conduzido no Aviário da Fazenda Experimental da Universidade Estadual do Oeste do Paraná, Campus Marechal Cândido Rondon - Paraná, onde 768 frangos de corte da linhagem comercial Cobb 500, com peso médio de $1,700 \mathrm{Kg}$, foram distribuídos em 48 unidades experimentais. Adotou-se o delineamento experimental inteiramente casualizado em esquema fatorial $4 \times 4$, sendo quatro níveis de energia metabolizável (3.000, 3.120, 3.240, 3.360 kcal.kg$\left.{ }^{1}\right)$ e quatro níveis de lisina digestível $(0,800 ; 0,900$; 1,000 e $1,100 \%$ ), totalizando 16 tratamentos com três repetições e 16 aves por unidade experimental.

As dietas experimentais foram formuladas à base de milho e farelo de soja (Tabela 1), de acordo com a composição dos alimentos e exigências nutricionais propostas por Rostagno et al. (2011). De 1 a 35 dias de idade, as aves foram criadas recebendo água e ração farelada à vontade, de acordo com a fase de criação. Aos 35 dias as aves foram pesadas individualmente e distribuídas uniformemente nas diferentes unidades experimentais

Ao final do período experimental, duas aves por repetição, com peso médio da unidade experimental foram pesadas e selecionadas para determinação do rendimento de carcaça. Esses frangos foram submetidos a oito horas de jejum, insensibilizados e sacrificados por deslocamento cervical de acordo com os princípios éticos de experimentação animal. Após a sangria pela veia jugular, as aves foram depenadas manualmente e evisceradas, para a obtenção das carcaças. Foram avaliados o peso absoluto $(\mathrm{g})$ e o rendimento (\%) das carcaças evisceradas e dos cortes nobres (peito, coxa, sobre coxa e asa). Na determinação do rendimento, foi considerado o peso da carcaça limpa e eviscerada, em relação ao peso vivo do animal em jejum. Para os cortes nobres, os cálculos dos rendimentos foram feitos em relação ao peso da carcaça eviscerada.
A gordura abdominal foi constituída pelo tecido adiposo presente ao redor da cloaca, moela, proventrículo e dos músculos abdominais adjacentes, sendo calculada em relação ao peso da carcaça eviscerada.

$\mathrm{TDP}=(\mathrm{QPcf}-\mathrm{QPci}) / \mathrm{PE}$, em que:

$\mathrm{QPcf}=$ quantidade, em gramas, de proteína na carcaça final; QPci= quantidade de proteínas, em gramas, na carcaça inicial; e $\mathrm{PE}=$ período experimental em dias. A QPcf foi obtida multiplicando-se o peso médio da carcaça das aves de cada unidade experimental, ao final do experimento, pelo respectivo teor de proteína bruta da carcaça, enquanto a QPci foi obtida pelo peso médio da carcaça do grupo de cinco pintos abatidos inicialmente, multiplicando-se por seu teor médio de proteína bruta.

A taxa de deposição de gordura (TDG) foi calculada segundo a equação:

$\mathrm{TDG}=(\mathrm{QGcf}-\mathrm{QGci}) / \mathrm{PE}$, em que:

QGcf= quantidade, em gramas, de gordura na carcaça final; QGci= quantidade de gordura na carcaça inicial; e $\mathrm{PE}=$ período experimental, em dias. QGef e QPci foram obtidas de modo similar às QPcf e QPci, utilizando-se os valores de extrato etéreo da carcaça.

As análise estatística foram realizadas com o auxílio do programa Statistical Analysis System versão 9 (SAS, 2002). As análises estatísticas dos parâmetros avaliados foram realizadas pelo procedimento PROC GLM $(\mathrm{P} \leq 0,05)$. Nos parâmetros em que foram encontradas diferenças $(\mathrm{P} \leq 0,05)$ foi estimada a regressão polinomial utilizando-se o procedimento PROC REG. Para interações Energia Metabolizável x Lisina digestível significativas $(\mathrm{P} \leq 0,05)$ foram estimadas regressões de superfície de resposta utilizando o procedimento PROC RSREG conforme ajustamento dos dados. 


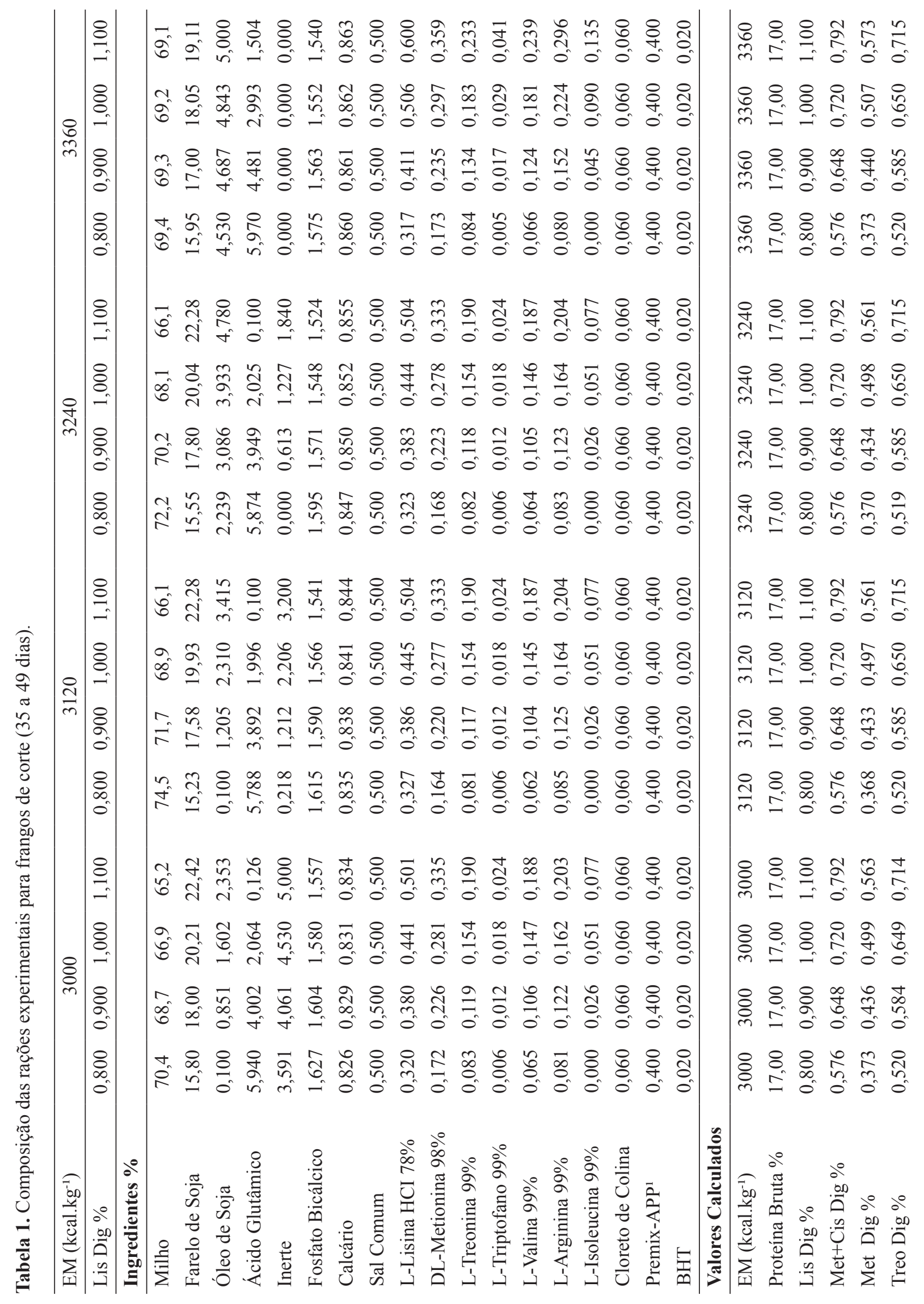




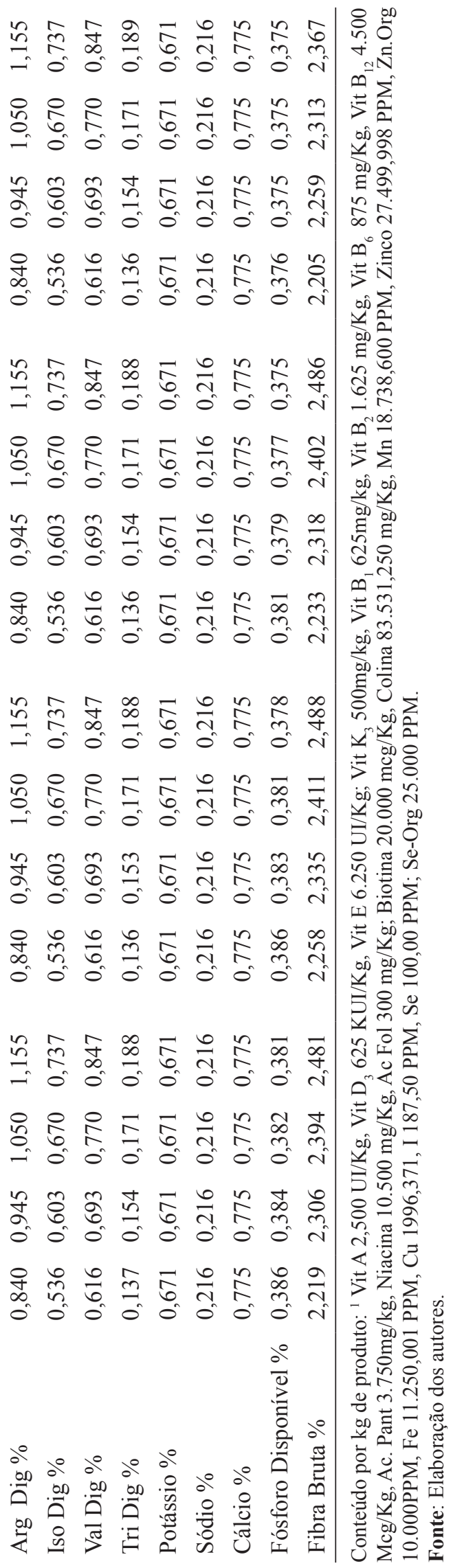




\section{Resultados e Discussão}

As características de carcaça e rendimento de frangos de corte estão apresentadas na Tabela 2. Não houve interação $(\mathrm{P}>0,05)$ entre os níveis de lisina digestível e energia metabolizável para o rendimento de carcaça e dos cortes avaliados. Da mesma forma, os níveis estudados também não interferiram de forma independente sobre todas as variáveis estudadas.

Tabela 2. Características de carcaça e rendimento dos cortes de frangos aos 49 dias de idade.

\begin{tabular}{ccccccc}
\hline Nível & Carcaça (\%) & Peito (\%) & Coxa (\%) & Sobrecoxa (\%) & Asa (\%) & Gordura Abdominal (\%) \\
\hline \multicolumn{7}{c}{ Energia Metabolizável $\left(\mathrm{kcal}^{\left.-\mathrm{kg}^{-1}\right)}\right.$} \\
\hline 3000 & 73,17 & 36,74 & 14,26 & 15,76 & 10,36 & 2,30 \\
3120 & 72,41 & 36,16 & 14,36 & 15,69 & 10,40 & 2,47 \\
3240 & 73,04 & 34,60 & 14,31 & 15,23 & 10,56 & 2,84 \\
3360 & 73,20 & 36,01 & 14,03 & 15,44 & 10,35 & 2,74 \\
\hline \multicolumn{7}{c}{ Lisina Digestível (\%) } \\
\hline 0,800 & 72,52 & 36,02 & 14,25 & 15,63 & 10,34 & 2,71 \\
0,900 & 72,44 & 36,09 & 14,32 & 15,55 & 10,63 & 2,45 \\
1,000 & 73,72 & 35,43 & 14,42 & 15,33 & 10,48 & 2,58 \\
1,100 & 73,14 & 35,98 & 13,95 & 15,62 & 10,22 & 2,60 \\
\hline Média & 72,96 & 35,88 & 14,24 & 15,53 & 10,42 & 2,59 \\
CV(\%) & 4,56 & 8,75 & 6,89 & 10,44 & 7,55 & 23,82 \\
\hline
\end{tabular}

CV: coeficiente de variação.

Fonte: Elaboração dos autores.

Lana et al. (2005) não encontraram variação no rendimento de carcaça e gordura abdominal de frangos da linhagem Avian Farms abatidos aos 42 dias de idade recebendo ração com diferentes níveis de lisina. Em trabalho realizado por Sakomura et al. (2004) também não foram observadas diferenças significativas pelos níveis de energia metabolizável $\left(3.050 ; 3.200 ; 3.350 \mathrm{kcal}^{\mathrm{kg}} \mathrm{kg}^{-1}\right)$ para frangos machos abatidos aos 43 dias de idade. Por outro lado, segundo Lima et al. (2008), o desempenho biológico e o econômico são afetados pelo nível energético das rações em frangos de corte.

Barbosa et al. (2008), avaliando efeitos dos níveis de energia metabolizável na fase final (22 a 49 dias) sobre o desempenho e as características de carcaça de frangos de corte da linhagem Hubbard, verificaram que os níveis de energia da dieta não afetam os rendimentos de carcaça, coxa, sobrecoxa, asa, tulipa, moela, coração, fígado, proventrículo e intestino. Entretanto, observaram que a gordura abdominal aumenta e o rendimento de peito decresce proporcionalmente à elevação da energia da dieta.

Em relação à gordura abdominal, os resultados deste estudo foram compatíveis com os dados obtidos por Duarte et al. (2012), onde não houve efeito significativo entre os níveis de energia (3200 e $3600 \mathrm{kcal} . \mathrm{kg}^{-1}$ ) estudados para frangos de corte da linhagem Cobb de 42 a 57 dias de idade. Isto pode ter ocorrido devido ao curto período do experimento (14 dias), tempo insuficiente para ocorrer deposição de gordura abdominal.

O nível de $0,9 \%$ de lisina digestível do presente trabalho proporcionou o menor percentual de deposição de gordura abdominal (2,45\%). Esse resultado diverge do trabalho realizado por Trindade Neto et al. (2009) que estimaram o nível de 1,00\% como ótimo para esta característica avaliada para 
frangos de corte machos da linhagem Ross aos 49 dias de idade. A divergência desses resultados pode ser explicado por Café (2001), que diz que a retirada manual da gordura abdominal da carcaça faz com que haja muita variação nos valores, levando a altos coeficientes de variação e tornando baixa a sensibilidade do teste estatístico em detectar diferenças significativas.

$\mathrm{Na}$ Tabela 3 são apresentados os resultados da taxa de deposição de proteína (TDP) e taxa de deposição de gordura (TDG) na carcaça dos frangos de corte no período de 35 a 49 dias de idade.

Tabela 3. Composição química da carcaça de frangos de corte aos 49 dias de idade.

\begin{tabular}{|c|c|c|c|c|c|c|}
\hline & PB na MN $(\%)$ & TDP (g/dia) & G na MN (\%) & TDG (g/dia) & MS (\%) & Umidade $(\%)$ \\
\hline \multicolumn{7}{|c|}{ Energia Metabolizável (kcal.kg $\left.{ }^{-1}\right)$} \\
\hline 3000 & 12,256 & 16,420 & 13,467 & 11,219 & 29,761 & 70,239 \\
\hline 3120 & 12,344 & 16,580 & 14,698 & 13,710 & 29,958 & 70,042 \\
\hline 3240 & 12,973 & 18,156 & 13,944 & 12,980 & 30,483 & 69,518 \\
\hline 3360 & 12,223 & 16,507 & 15,483 & 15,172 & 30,627 & 69,373 \\
\hline \multicolumn{7}{|c|}{ Lisina Digestível (\%) } \\
\hline 0,800 & 12,293 & 15,782 & 15,044 & 13,182 & 31,729 & 68,271 \\
\hline 0,900 & 12,431 & 16,787 & 14,115 & 12,708 & 29,743 & 70,258 \\
\hline 1,000 & 12,453 & 16,884 & 14,095 & 12,442 & 30,217 & 69,783 \\
\hline 1,100 & 12,791 & 18,315 & 14,374 & 14,910 & 29,140 & 70,860 \\
\hline Média & 12,470 & 16,942 & 14,407 & 13,310 & 30,207 & 69,793 \\
\hline $\mathrm{CV}(\%)$ & 3,79 & 6,78 & 6,16 & 11,74 & 7,75 & 3,35 \\
\hline \multicolumn{7}{|c|}{ Análise de Regressão } \\
\hline \multicolumn{7}{|c|}{ Energia Metabolizável $\left(\mathrm{kcal} \mathrm{kg}^{-1}\right)$} \\
\hline Linear & 0,552 & 0,461 & 0,002 & 0,001 & 0,140 & 0,141 \\
\hline Quadrática & 0,020 & 0,076 & 0,729 & 0,793 & 0,793 & 0,739 \\
\hline \multicolumn{7}{|c|}{ Lisina Digestível (\%) } \\
\hline Linear & 0,33 & 0,001 & 0,237 & 0,183 & 0,044 & 0,044 \\
\hline Quadrática & 0,538 & 0,6558 & 0,127 & 0,063 & 0,331 & 0,331 \\
\hline EM x LD* & - & 0,0081 & 0,0006 & $<0,0001$ & - & - \\
\hline
\end{tabular}

PB: proteína bruta, TDP: taxa de deposição de proteína, G: gordura, TDG: taxa de deposição de gordura, MS: matéria seca, CV: coeficiente de variação, *SR: superfície de resposta, MN: matéria natural.

Fonte: Elaboração dos autores.

O teor de proteína bruta na carcaça teve efeito $(\mathrm{P}<0,05)$ em função dos níveis de energia metabolizável $\left(\mathrm{PB}=-141,29962+0,09665^{*} \mathrm{EM}\right.$ - 0,00001516*EM²; R ${ }^{2}$ 0, 41). A utilização de 3187,66 kcal. $\mathrm{kg}^{-1}$ de EM nas dietas proporcionaram os maiores valores de proteína bruta na carcaça. Resultados diferentes foram obtidos por Ton et al. (2011) que observaram interação entre os níveis de lisina digestível e energia metabolizável para o teor de proteína na carcaça, em codornas de corte aos 35 dias de idade. Com o aumento da idade, a deposição de proteína caí mais marcadamente do que a deposição de gordura. Isso porque o aumento da proteína corporal ocorre em um período limitado do desenvolvimento (GONZÁLES; SARTORI, 2002).

Houve interação $(\mathrm{P}<0,05)$ entre os níveis de energia metabolizável e lisina digestível sobre 
a taxa de deposição de proteína (TDP) e de gordura (TDG) e o teor de gordura na carcaça (G). A melhor taxa de deposição de proteína foi obtida para o nível de $1,100 \%$ de $\operatorname{LD}$ e $3240 \mathrm{kcal} . \mathrm{kg}^{-1}$ de EM $(\mathrm{TDP}=-333,684356+$ $35,845883 * \mathrm{LD}+0,206457 * \mathrm{EM}+12,415078 * \mathrm{LD}^{2}$ - 0,000029830*EM ${ }^{2}-0,016258 *$ LDxEM; R $^{2} 0,53$ ) (Figura 1). Um estudo realizado sobre o efeito da linhagem (Ross 508 e Cobb 500) e o nível de lisina em frangos de corte aos 42 dias de idade, observaram que a linhagem Ross 308 apresentou melhor rendimento de carne de peito. Isso demonstra que a composição corporal pode ser o parâmetro que explica as diferenças entre linhagens quanto às exigências de lisina. Pois se a linhagem Ross 308 apresenta maior deposição de proteína e menor de gordura, esta pode apresentar exigência maior de lisina (PAVAN et al., 2003).

Figura 1. Taxa de deposição de proteína de frangos de corte de 35 a 49 dias de acordo com os níveis de energia metabolizável e lisina digestível na ração.

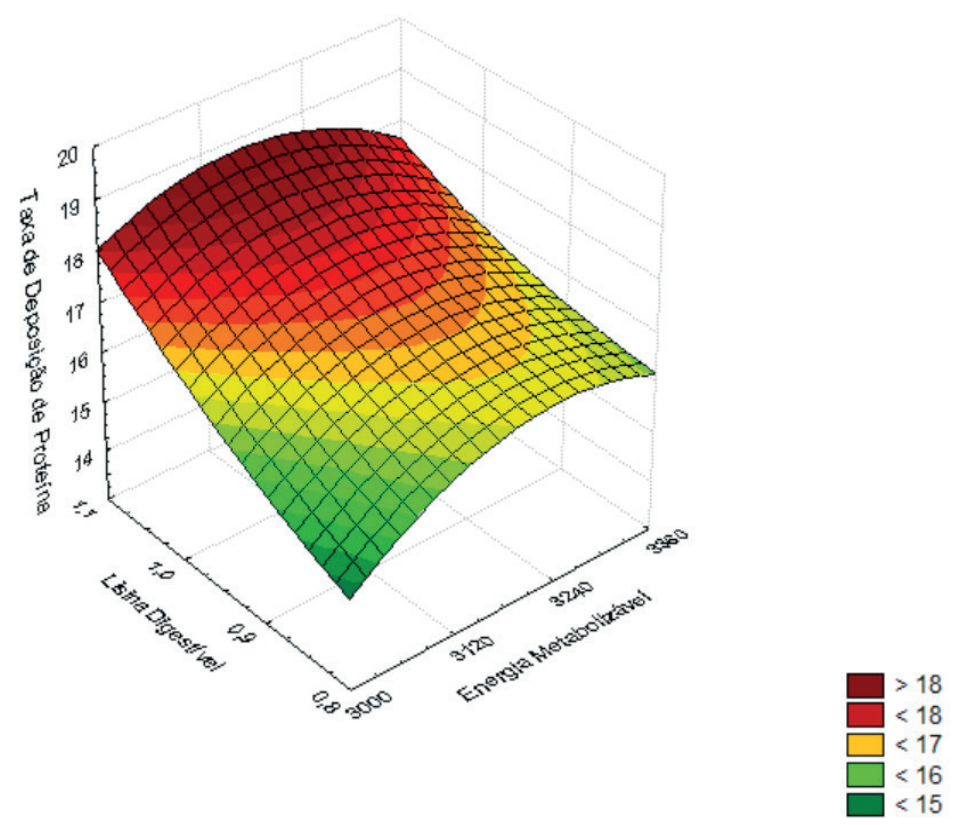

Fonte: Elaboração dos autores.

Os resultados no presente trabalho diferem dos obtidos por Mendonça et al. (2008), onde os níveis de energia metabolizável estudados nas três fases (21, 49 e 70 dias de idade) não influenciaram a deposição de proteína corporal das aves. Estes autores afirmaram que a deposição protéica é controlada pela genética da ave, independentemente da ingestão de energia.

A taxa de deposição de gordura e o teor de gordura apresentaram os melhores resultados para o nível de 1,000 \% de LD e 3000 kcal. $\mathrm{kg}^{-1}$ de EM, de acordo com as equações, respectivamente (TDG $=-374,066524+108,924111 * \mathrm{LD}+0,19914 * \mathrm{EM}$ $+\quad 84,559160 * \mathrm{LD}^{2} \quad-\quad 0,000017377 * \mathrm{EM}^{2}$ $\left.-0,082950 * \mathrm{LDxEM} ; \mathrm{R}^{2} 0,63\right)$ (Figura 2) e $(\mathrm{G}=$ $-35,021371+26,257994 * \mathrm{LD}+0,018731 * \mathrm{EM}$ $+\quad 34,464137 * \mathrm{LD}^{2}+\quad 0,000002150 * \mathrm{EM}^{2} \quad$ $0,029245^{*}$ EMxLD; $\left.\mathrm{R}^{2}=0,53\right)$. O maior teor de gordura ocorreu no tratamento com o maior nível de energia metabolizável (3360 kcal. $\mathrm{kg}^{-1}$ ), prejudicando a qualidade da carcaça (Figura 3).

Mendonça et al. (2008) verificaram que os 
níveis de energia utilizados na dieta não afetaram a deposição de gordura em frangos machos, no período de 22 a 49 dias de idade. Porém, as aves mostraram aumento linear na deposição de gordura quando fornecidos níveis maiores de energia na ração, sendo a maior deposição no nível de 3300 kcal.kg-1 de EM resultado similar ao obtido no presente trabalho.

Desta forma, devemos ressaltar que a composição corporal não é somente afetada por fatores nutricionais, mas também por fatores genéticos, ambientais e fisiológicos.

Figura 2. Taxa de deposição de gordura de frangos de corte de 35 a 49 dias de acordo com os níveis de energia metabolizável e lisina digestível na ração.

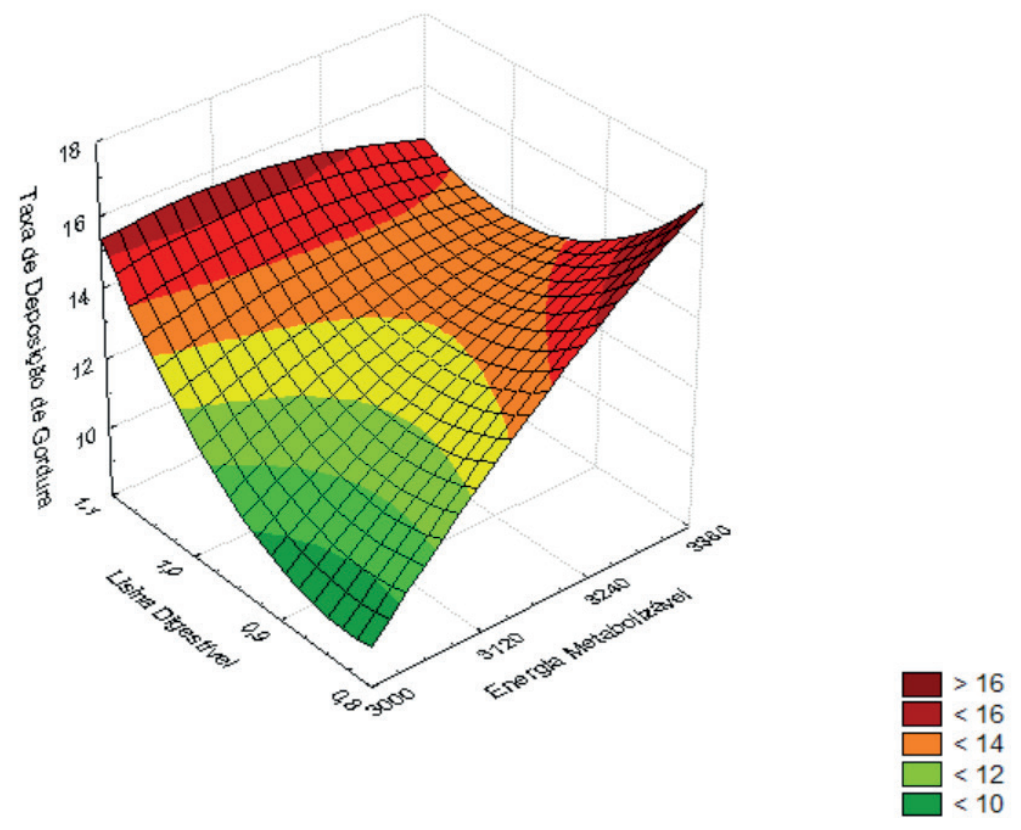

Fonte: Elaboração dos autores. 
Figura 3. Teor de gordura de frangos de corte de 35 a 49 dias de acordo com os níveis de energia metabolizável e lisina digestível na ração.

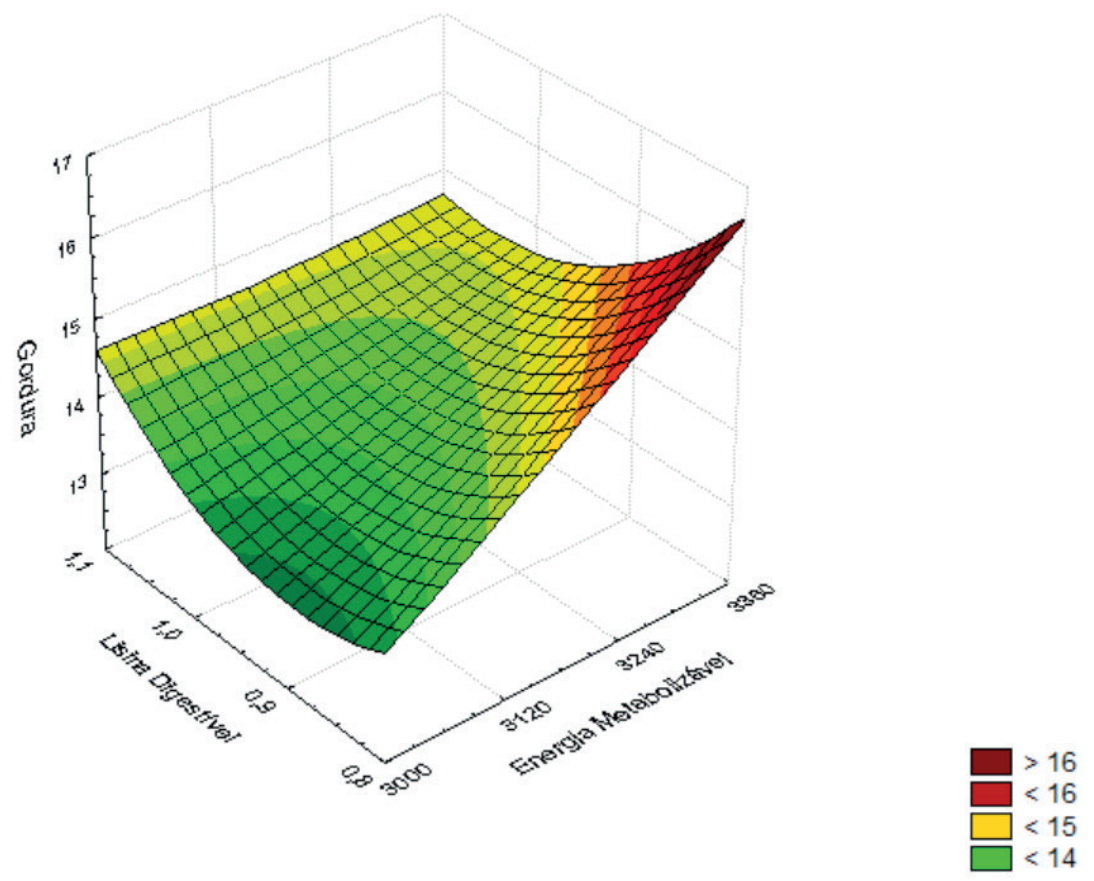

Fonte: Elaboração dos autores.

\section{Conclusões}

Os níveis de lisina digestível e energia metabolizável estudados não afetaram o rendimento de carcaça, rendimento de cortes e a porcentagem de gordura abdominal nos frangos de corte de 35 a 49 dias.

Altos níveis de energia metabolizável na dieta podem prejudicar a qualidade de carcaça de frangos de corte, ao aumentar o teor de gordura abdominal.

A melhor taxa de deposição de proteína foi obtida para o nível de $1,100 \%$ de LD e 3240 kcal. $\mathrm{kg}^{-1}$ de EM, no entanto esse nível de lisina aumenta a taxa de deposição de gordura na carcaça.

\section{Referências}

AJINOMOTO. Aminoácidos para nutrição de frangos de corte. São Paulo: Ajinomoto, 2012. Disponível em: <http://www.lisina.com.br/publicacoes_detalhes. aspx id=2189> . Acesso em: 20 fev. 2013.

BAKER, D. H. Advances in protein - amino acid nutrition of poultry. Amino Acids, Münster, v. 37, n. 1, p. 29-41, 2009.

BARBOSA, F. J. V.; LOPES, J. B.; FIGUEIREDO, A. V.; ABREU, M. L. T.; DOURADO, L. R. B.; FARIAS, L. A.; PIRES, J. E. P. Níveis de energia metabolizável em rações para frangos de corte mantidos em ambiente de alta temperatura. Revista Brasileira de Zootecnia, Viçosa, v. 37, n. 5, p. 849-855, 2008.

CAFÉ, M. B. Influência de diferentes niveis de metionina e lisina no desempenho e nas características de carcaça de frangos de corte. 2001. Tese (Doutorado em Zootecnia) - Universidade Estadual Paulista, Jaboticabal.

DUARTE, K. F.; JUNQUEIRA, O. M.; BORGES, L. L.; SANTOS, E. T.; MARQUES, R. H.; QUADROS, T. C. O.; DOMINGUES, C. H. F. Desempenho e morfometria duodenal de frangos de corte submetidos a diferentes níveis de energia e programas de alimentação de 42 a 57 dias de idade. Ciência Animal Brasileira, Goiânia, v. 13, n. 2, p. 197-204, 2012.

FRAGA，A. L; MOREIRA, I.; FURLAN, A. C.; BASTOS, A. O.; OLIVEIRA, R. P.; MURAKAMI, A.E. Lysine requirement of start barrow from two genetic groups fed on low crude protein diets. Brazilian Archives of Biology and Technology, Curitiba, v. 51, n. 1, p. 49-56, 2008. 
GAYA, L. G.; MOURÃO, G. B.; FERRAZ, J. B. S. Aspectos genético-quantitativos de características de desempenho, carcaça e composição corporal em frangos. Ciência Rural, Santa Maria, v. 36, n. 2, p. 709-716, 2006.

GONZALES, E.; SARTORI, J. R. Crescimento e metabolismo muscular. In: MACARI, M.; FURLAN, R. L.; GONZALES, E. (Ed.). Fisiologia aviária aplicada a frangos de corte. Jaboticabal: FUNEP/UNESP, 2002. $375 \mathrm{p}$.

KIDD, M. T.; CORZO, A.; HOEHLER, D.; MILLER, E. R.; DOZIER, W. A. Broiler responsiveness (Ross $\times 708$ ) to diets varying in amino acid density. Poultry Science, Champaign, v. 84, n. 9, p. 1389-1396, 2005.

LABADAN, M. C.; HSU, K. N.; AUSTIC, N. E. Lysine and arginine requirements of broilers chickens at two to three weeks of age. Poultry Science, Champaign, v. 80, n. 5, p. 599-606, 2001.

LANA, S. R. V.; OLIVEIRA, R. F. M.; DONZELE, J. L.; GOMES, P. C.; VAZ, R. G. M. V.; REZENDE, W. O. Níveis de lisina digestível em rações para frangos de corte de 22 a 42 dias de idade, mantidos em temperatura de termoneutralidade. Revista Brasileira de Zootecnia, Viçosa, v. 34, n. 5, p. 1624-1632, 2005.

LIMA, L. M. B.; LARA, L. J.; BAIAO, N. C.; CANÇADO, S. V.; MICHELL, B. C.; FERREIRA, F. C. Efeitos dos níveis de energia, lisina e metionina + cistina sobre o desempenho e rendimento de frangos de corte. Revista Brasileira de Zootecnia, Viçosa, v. 37, n. 8, p. 1424-1432, 2008.

MELLO, H. H. C.; GOMES, P. C.; ROSTAGNO, H. S.; ALBINO, L. F. T.; SOUZA, R. M.; CALDERANO, A. A. Valores de energia metabolizável de alguns alimentos obtidos com aves de diferentes idades. Revista Brasileira de Zootecnia, Viçosa, v. 38, n. 5, p. 863-868, 2009.

MENDONÇA, M. O.; SAKOMURA, N. K.; SANTOS, F. R.; FREITAS, E. R.; FERNANDES, J. B. K.; BARBOSA, N. A. A. Níveis de energia metabolizável para machos de corte de crescimento lento criados em semiconfinamento. Revista Brasileira de Zootecnia, Viçosa, v. 37, n. 8, p. 1433-1440, 2008.
MOREIRA, J.; MENDES, A. A.; GARCIA, R. G.; NAAS, I. A.; MIWA, I. Efeito da densidade de criação e do nível de energia da dieta sobre o desempenho e rendimento de carcaça em frangos de corte. Revista Brasileira de Ciência Avícola, Campinas, v. 3, p. 39, 2001. Suplemento 3.

PAVAN, A. C.; MENDES, A. A.; OLIVEIRA, E. G.; DENADAI, J. C.; GARCIA, R. G.; TAKITA, T. S. Efeito da linhagem e do nível de lisina da dieta sobre a qualidade da carne do peito de frangos de corte. Revista Brasileira de Zootecnia, Viçosa, v. 32, n. 6, p.1732-1736, 2003. Suplemento 1.

ROSTAGNO, H. S.; ALBINO, L. F. L.; DONZELE, J. L.; GOMES, P. C.; OLIVEIRA, R. F.; LOPES, D. C.; FERREIRA, A. S.; BARRETO, S. L. T.; EUCLIDES, R. F. Tabelas brasileiras para aves e suínos: composição de alimentos e exigências nutricionais. 3. ed. Viçosa: UFV, 2011. 252 p.

SAKOMURA, N. K.; LONGO, F. A.; RABELLO, C. B.; WATANABE, K.; PELICIA, K.; FREITAS, E. R. Efeito do nível de energia metabolizável da dieta no desempenho e metabolismo energético de frangos de corte. Revista Brasileira de Zootecnia, Viçosa, v. 33, n. 6, p. 1758-1767, 2004. Suplemento 1.

SILVA, D. J.; QUEIROZ, A. C. D. Análise de alimentos: métodos químicos e biológicos. 3. ed. Viçosa: UFV, 2004. 235 p.

STATISTICALANALYSIS SYSTEM-SAS INSTITUTE INC. Statistical analysis system user's guide. Version 9. Cary: Statistical Analysis System Institute, 2002. 513 p.

TON, A. P. S.; FURLAN, A. C.; MARTINS, E. N.; TOLEDO, J. B.; SCHERER, C.; CONTI, A. C. M. Exigências de lisina digestível e de energia metabolizável para codornas de corte em crescimento. Revista Brasileira de Zootecnia, Viçosa, v. 40, n. 3, p. 593-601, 2011.

TRINDADE NETO, M. A.; TAKEARA, P.; TOLEDO, A. L.; KOBASHIGAWA, E.; ALBUQUERQUE, R.; ARAUJO, L. F. Níveis de lisina digestível para frangos de corte machos no período de 37 a 49 dias de idade. Revista Brasileira de Zootecnia, Viçosa, v. 38, n. 3, p. 508-514, 2009. 
